\title{
OS ESTÁGIOS DE APRENDIZAGEM DA ESCRITURA PELA CRIANÇA: UMA NOVA LEITURA PARA UM ANTIGO TEMA
}

Cláudia Martins Moreira*

\begin{abstract}
Resumo: Este trabalho faz uma revisão dos estágios de aquisição da escrita à luz da Linguística Aplicada, e fornece uma alternativa diversa dos conhecidos estágios ferreirianos, muito utilizados pelo professor alfabetizador. Para tal, lanço mão de achados e conclusões fornecidos pelos estudos de aquisição da escrita, de orientação fonológica (ABAURRE, 1998, 1999; CAGLIARI, 1992a, 1992b, 1998), bem como de estudos de aquisição da linguagem que evidenciam o papel do molde silábico no processo aquisicional (McNEILAGE; DAVIS, 1990). São utilizados, como corpora, os registros da pesquisa de campo e experimental realizada ao longo do ano letivo de 2006, com 20 crianças de escolas públicas da cidade de Salvador, em cinco encontros periódicos individuais de produção escrita. Tais produções me permitem concluir que o percurso da aquisição da escrita inicia-se com a ausência de relação grafo-fônica, passando por uma série de etapas cíclicas de relações som/letra, até atingirem as relações ortográficas, cuja dependência som/grafia é superada.
\end{abstract}

Palavras-chave: escrita; fonologia; aquisição; alfabetização; estágios.

\section{INTRODUÇÃO}

Desde a década de 80, no Brasil como em outros países latinos, é impossível falar de alfabetização sem mencionar a importante contribuição de Emília Ferreiro para a compreensão de como a criança constrói progressivamente suas hipóteses sobre a escrita.

\footnotetext{
* Professora de Língua Portuguesa e Linguística da Universidade Estadual de Santa Cruz (UESC), Santa Cruz, Bahia, Brasil. Doutora em Letras.E-mail: <claudia@uesc.br>.
} 
Consequentemente, embora a autora deixe claro que não é sua intenção propor uma metodologia de ensino para a alfabetização, a repercussão de suas reflexões foram imediatas no sentido de alterar a maneira como coordenadores pedagógicos, gestores e professores viam o ensino de alfabetização.

Nunca antes na história houvera um reflexo tão rápido entre teoria e prática na escola como foi o construtivismo baseado nas reflexões de Ferreiro. E isso tem suas consequências positivas, mas também deu origem a muitos equívocos, que serão discutidos neste trabalho.

Por outro lado, muitas pesquisas a respeito do processo de aquisição da linguagem e, consequentemente, da escrita, eram feitas por linguistas, em diversas partes do país, quase concomitantemente à de Ferreiro e Teberosky (1985), a exemplo dos trabalhos de Kato (1985) e Alvarenga (1988), além de uma série de outros obras de destaque, como as de Abaurre (1998, 1999, entre outros). Todavia, tais trabalhos não chegaram a ter uma repercussão maciça - senão algumas contribuições pontuais, em geral mais concentradas na região Sul e Sudeste do país no ensino de alfabetização.

Assim, visando efetivar esse diálogo urgente e necessário, o que pretendo neste trabalho é oferecer uma proposta alternativa aos estágios de aprendizagem da escritura ${ }^{1}$ pela criança, proposta esta fundada num referencial diferente da teoria Psicogenética (consagrada no âmbito da Escola Fundamental). A apresentação de uma nova proposta visa a fornecer outra explicação possível (do ponto de vista da Linguística, especialmente da Fonologia) ao desenvolvimento da escritura pela criança; além disso, busca preencher uma lacuna teórica, visto que a ausência de tal proposta tem levado muitos estudiosos, especialmente os estudiosos da linguagem - linguistas, fonoaudiólogos, psicólogos, entre outros - a optarem por uma terminologia que muitas vezes não condiz com o referencial teórico com o qual se trabalha.

\footnotetext{
${ }^{1}$ Em alguns estudos, a palavra "escrita" costuma ser utilizada tanto para referir-se ao sistema de escrita de uma língua como para fazer menção à atividade de escrever. Neste trabalho, visando diferenciar esses dois aspectos, utilizarei a palavra "escrita" como sinônimo de sistema de escrita, ou de material escrito, enquanto a palavra "escritura" deverá referir-se à atividade de escrever (análoga à "leitura", como atividade de ler).
}

MOREIRA - Os estágios de aprendizagem da escritura pela criança... 


\section{OS NÍVEIS DE ESCRITA ${ }^{2}$ NUMA PERSPECTIVA PSICOGENÉTICA: A TEORIA E SEUS VIESES}

Um dos principais trabalhos que buscam explicar o processo de aprendizagem do código escrito pela criança é o livro "Psicogênese da língua escrita" (FERREIRO; TEBEROSKY, 1985). Nesse, propõem-se níveis evolutivos por que passam as crianças no seu processo de aprendizagem do código escrito, tomando como suporte a teoria Psicogenética de Jean Piaget, e utilizando-se de dados de pesquisa experimental, realizada pelas próprias autoras.

Segundo elas, a primeira hipótese da criança é que a escrita representa o mundo de uma forma direta, não arbitrária, ou seja, os elementos que formam o sistema devem ser semelhantes àquilo que representam. Portanto, nessa fase, significante e significado se identificam, ou seja, a criança concebe a escrita como uma soma de desenhos representativos dos objetos: "O desenho pode ser interpretado, o texto serve para ler o que o desenho representa. Neste caso, como em muitos outros, a expectativa é a de que o texto corresponda ao desenho, o objeto representado em um também o está no outro" (FERREIRO; TEBEROSKY, 1985, p. 73).

Essa hipótese é ainda bastante rudimentar e não demora para ser descartada pela criança; na maioria das vezes, antes mesmo de sua entrada no ambiente escolar. Por outro lado, as autoras defendem, muito acertadamente (o que seus dados corroboram), que a passagem dessa hipótese para a seguinte dá-se de maneira progressiva. Todavia, ao investigar essa passagem, as autoras deixam algo sem resposta: a partir do momento em que a criança deixa de pensar que se escreve através de desenhos e que ler é interpretar desenhos, qual estatuto ganhariam, agora, os desenhos que acompanham o texto? Ou seja, já que as ilustrações perdem o papel do portador do sentido, que papel, então, elas passam a ter, uma vez que continuam acompanhando os textos? Tal aspecto foi tratado por nossa equipe de pesquisa, em 2003 (SILVA; MOREIRA, 2003).

\footnotetext{
2 A palavra "escrita" será mantida com o sentido de usual (polissêmico), para respeitar o uso que dela faz a teoria psicogenética, que será discutida neste artigo.
} 
O próximo passo que a criança dá na evolução das suas hipóteses, de acordo com essas autoras, é a percepção do caráter arbitrário e convencional do sistema de escrita. Ela já sabe que a escrita é formada por símbolos e que esses símbolos não representam diretamente a realidade. Significante e significado começam a se distinguir. No entanto, a criança ainda não sabe qual símbolo usar para representar o que ela quer. Em geral, se for pedido que ela escreva, escreverá as letras que já conhece (quase sempre as letras do seu nome), indistintamente. Convencionou-se denominar essa hipótese como Pré-Silábica. Muitos autores atribuem essa terminologia ao trabalho que estou apreciando aqui; entretanto, trata-se de um equívoco. Ferreiro e Teberosky (1985) não utilizam tal terminologia neste trabalho, nem em nenhum dos outros apreciados (FERREIRO, 1987, 1990, 2002, 2007a, 2007b); inclusive não dão a essa hipótese a atenção que merece. Acredito que a relação oralidade/escrita não é acionada apenas a partir da hipótese Silábica (como propõem as autoras), mas desde muito antes, como demonstrarei no próximo capítulo. Também não concordo com a terminologia adotada (Pré-silábico) por razões que explicitarei adiante.

Ainda segundo as autoras (FERREIRO; TEBEROSKY, 1985), depois do estágio anterior, em contato com material escrito - e motivada pela escola - a criança começa a perceber que o sistema de escrita do português se baseia no som; ou seja, não é pictográfica, ou ideográfica, como ela pensava antes; nossa escrita é, basicamente, fonográfica. Entretanto, a menor unidade sonora que ela representa, nesta fase, é a sílaba. Para explicitar essa concepção, as autoras analisam a escrita infantil e observam que a quantidade de caracteres utilizados pela criança é similar à quantidade de sílabas da palavra; mas nem sempre essas letras têm relação com as sílabas que ela deseja representar. No início, a preocupação maior é com a quantidade de letras, não com o tipo de letra que se usa. Aos poucos, as representações vão se aproximando das letras que formam o nome (por exemplo, para a palavra "boneca", ela escreve BNC). Nisso consiste a hipótese Silábica.

O maior mérito dessa obra é certamente a ênfase que as autoras dão à hipótese Silábica. Chegam mesmo a afirmar:

A mudança qualitativa consiste em que: a) se supera a etapa de uma correspondência global entre forma escrita e a expressão oral 
(recorte silábico do nome); mas, além disso, b) pela primeira vez a criança trabalha claramente com a hipótese de que a escrita representa partes sonoras da fala. (FERREIRO; TEBEROSKY, 1985, p. 193)

Gradativamente, a criança vai percebendo que as letras representam os sons; todavia, ela ainda não se libertou completamente da hipótese silábica, tanto que, algumas vezes, representa a sílaba, outras vezes, representa o fonema. Ela se encontra na hipótese SilábicoAlfabética, segundo as referidas autoras.

Quando a criança é capaz de compreender que cada letra da escrita pode representar um fonema, ela se encontra numa hipótese Alfabética. Ela está alfabetizada no sentido restrito.

Nesse momento, observa-se uma lacuna profunda na obra das autoras. Uma vez que não é objetivo da obra uma análise da influência da língua falada sobre o processo de alfabetização, Ferreiro e Teberosky (1985) dão por encerradas as hipóteses de aquisição, deixando de lado o período de maior dificuldade para as crianças, dificuldades que elas não conseguem resolver sozinhas, e muito menos com a ajuda do professor, pois a teoria que embasa a pedagogia construtivista brasileira não fornece subsídio para tal.

São os teóricos da linguagem que investem nesse aspecto. Um dos primeiros trabalhos que contribui para entender essa questão é o Guia teórico do alfabetizador (LEMLE, 1993). Nessa obra, a autora mostra que a criança começa acreditando numa relação biunívoca entre letra e som (uma letra para cada som e vice-versa) depois, passa a perceber as relações mais complexas (uma letra representando diferentes sons ou um som sendo representado por letras diferentes). Por fim, ela percebe os casos arbitrários e se dá conta de que muitos aspectos da escrita precisam ser memorizados (como, por exemplo, quando se propõe escrever a palavra "caixa" e se questiona: é com "x" ou com "ch"?). Nesse momento, diz-se que a criança entrou no nível Ortográfico, que perdurará por toda a vida.

Retomando a conhecida defesa das autoras quanto à maneira como seus achados devem ser interpretados: "é conveniente esclarecer que não pretendemos propor nem uma nova metodologia da aprendizagem nem uma nova classificação dos transtornos da 
aprendizagem" (FERREIRO; TEBEROSKY, 1985, p. 15), conclui-se que a pedagogia da alfabetização que se instituiu no Brasil, a partir das pesquisas de Ferreiro, estão permeadas de releituras ao modo de fazer ensino de alfabetização no nosso país. A ênfase na pedagogia ideovisual, a mitificação do respeito ao "erro", a negação total da fonetização, a precariedade da intervenção do professor (em nome do "respeito" à criança) parecem uma tentativa, em muitos aspectos, equivocada, de transpor a teoria para a prática.

\section{OS ESTUDOS LINGUÍSTICOS SOBRE A ESCRITA: A TEORIA E OS PARCOS DIÁLOGOS COM A ESCOLA}

Já foi dito, inicialmente, que a Linguística, especialmente no que tange à área de Aquisição da Escrita, já tem uma vasta produção no Brasil. $\mathrm{E}$ justamente pela sua vastidão, serão citadas aqui apenas aquelas que, por um lado, conseguem cobrir as lacunas deixadas pela teoria Psicogenética; e, por outro lado, que mais se aproximam do tema deste trabalho em particular, qual seja, os níveis de aquisição da escrita.

\subsection{Estudos sobre o letramento emergente: o que faltava ser dito}

Interessa, aos estudiosos de letramento, compreender a aprendizagem da escrita enquanto objeto socialmente construído, e, por outro lado, compreender a repercussão desse objeto sobre a conduta do sujeito que o adquire. Além disso, procura-se estudar em profundidade a interferência de aspectos sociais (como nível de escolaridade da família, frequência e tipos de contato com material escrito; e aspectos motivacionais) relacionados à aprendizagem da escrita, entre outros. Alguns trabalhos nessa área, como o de Rojo (1998), Mayrink-Sabinson (1998), Terzi (1995a) apontam tanto para a aprendizagem da escrita infantil como para a aprendizagem adulta.

O que há de comum entre esses estudos é a conclusão de que quanto maiores e mais diferenciadas forem as experiências da criança com textos escritos, maiores serão as chances de que ela tenha êxito na escola; pois, manuseando textos impressos, a criança familiariza-se com 
esses textos e conhece o papel da escrita para a sociedade. $\mathrm{Na}$ escola, ela apenas irá aprender aqueles aspectos que não podem ser aprendidos sem instrução explícita, quais sejam, no caso do português, as relações fonográficas e arbitrárias entre letra e som. Além disso, muitos dos estudos de letramento chegam à conclusão de que as reflexões acerca das propriedades da escrita da própria língua acontecem muito antes de a criança entrar na escola; e não são apenas reflexões acerca dos aspectos semânticos, como também de aspectos fonéticos e gráficos.

O conceito de letramento é motivo de muitas controvérsias no interior das pesquisas em alfabetização, principalmente entre linguistas e educadores. Para alguns estudiosos, o termo letramento propõe uma ruptura entre a aprendizagem de um código e o seu uso; ruptura considerada inaceitável por estudiosos como Gadotti (2005) e Ferreiro (2002).

$\mathrm{Na}$ perspectiva com que desenvolvo este trabalho, a diferenciação acima explicitada é fundamentalmente necessária, por dois motivos. Primeiro, porque permite distinguir os dois aspectos da aprendizagem da escrita: por um lado, a aprendizagem de uma técnica, um código convencionalizado (elaborado ao longo da evolução da humanidade); e, por outro lado, a aprendizagem do uso pragmático dessa técnica para fins de interação social. Entre esses dois aspectos não existe uma relação necessária e absoluta: pode-se obter certo nível de letramento, sem ser alfabetizado; ou se pode alfabetizar sem que se saiba utilizar tal conhecimento para efeito de interação social. Entretanto, para que se diga que uma criança "adquiriu a escrita”, o necessário e ideal é que ela a adquira sob esses dois aspectos.

O outro motivo porque opto por essa diferenciação merece uma maior atenção. Ao longo dos últimos vinte anos, tornou-se quase um "pecado" falar de método de alfabetização. Novamente, a escola faz uma leitura enviesada da obra de Ferreiro e Teberosky (1985). As autoras afirmam ali - com o que concordo - que o método de ensino não é o responsável direto pelo fracasso ou sucesso dos alunos. A intenção é minimizar o extremo valor que era dado ao método àquela época, enquanto se esquecia de considerar a criança enquanto sujeito de aprendizagem. O foco deixaria de ser como se ensina à criança passando-se a como a criança aprende. Ocorre que essas observações foram levadas tão ao extremo que a escola criou ojeriza à palavra "método" (como se fosse 
possível ensinar sem um método!). Quando se retoma a diferença entre aprendizagem de uma técnica e aprendizagem do uso, obriga-se a retomar essa discussão; porque fica evidente que, para ensinar uma "técnica", é necessário um "método", mesmo que se compreenda ser essa técnica apenas um meio para atingir o fim principal, qual seja, o uso da escrita para fins de interação social.

\subsection{Estudos sobre a aquisição da ortografia: aprendizagem do caráter arbitrário da escrita}

Já afirmei antes que a maior lacuna dos estudos psicogenéticos foi ter deixado de considerar a maneira como a criança constrói a ortografia da sua língua. Tenha sido proposital ou não, a verdade é que, sobre a base teórica em que se assentam tais pesquisas - as próprias autoras assumem a vinculação com Chomsky e Piaget - e tendo como objetivo central a proposição de universais ao processo de aquisição da escrita, não haveria como nem por que considerar tal aspecto.

Além do mais, para entender a aquisição da ortografia, necessário se faz uma compreensão detalhada dos efeitos da língua falada sobre o sistema de escrita e suas regras, bem como, a respeito desse mesmo efeito sobre a maneira como o aluno aprende. Restou, portanto, aos estudiosos da linguagem, a tarefa de compreender como as crianças lidam com as restrições da sua língua materna, num momento em que não é mais (apenas) a relação entre o oral e escrito o objeto de conflito, e sim, as regras que cada língua impõe ao usuário para que esse seja um leitor-escritor competente em sua língua materna escrita.

No interior dessas pesquisas sobre ortografia, estudam-se as fontes de dificuldade na aprendizagem das regras ortográficas (REGO; BUARQUE, 2002); a aprendizagem de grafemas complexos, como o dígrafo; a aprendizagem da pontuação (SILVA; BRAND ̃̃O, 2002) entre outros.

Apesar da importante contribuição teórica desses estudos, é lamentável o quanto têm sido pouco conhecidos pelos professores em sala de aula, especialmente na Bahia. Lamentável porque, uma vez conhecidos, poderiam alterar significativamente a maneira como as regras ortográficas tem sido ensinadas no âmbito escolar. E também 
lamentável, porque são justamente esses aspectos os causadores dos maiores conflitos entre educadores e aprendizes na escola.

\subsection{Estudos aquisicionais que iluminam a categorização dos níveis}

Do que foi dito até agora, a respeito da contribuição da Linguística ao ensino de alfabetização, restou referir-me a dois autores que, embora indiretamente, têm iluminado minhas reflexões a respeito dos níveis aprendizagem da escritura infantil. Trata-se de Cagliari (1981, 1992a, 1992b, 1998) e Abaurre (1998, 1999). Ambos - de formação em fonética e fonologia - têm dado contribuições fundamentais às reflexões linguísticas acerca da relação entre escrita e oralidade, mais especificamente, ambos têm mostrado como as crianças refletem sobre as estruturas da língua materna escrita que aprendem.

Os trabalhos de Cagliari são talvez os que tiveram mais repercussão no ensino de alfabetização no nosso estado, em virtude de sua frequênte presença nos nossos círculos pedagógicos e em cursos de formação continuada. Isso aliado à acessibilidade da sua linguagem. No livro Alfabetização e Linguística (1992a), o autor evidencia a similaridade entre a aquisição filogenética e ontogenética da escrita; além de servir como um importante guia ao professor no sentido de compreender os processos subjacentes aos "erros" das crianças.

Todavia, é especialmente no seu trabalho de 1998 que o autor faz uma crítica contundente às concepções construtivistas/psicogenéticas:

Com as novas idéias do construtivismo, alguns professores têm levado os trabalhos de alfabetização para o extremo oposto ao das cartilhas, também com graves consequências para alguns alunos. É o caso absurdo do professor que pretende tirar todos os conhecimentos a partir do aluno e, para tanto, acha que sua tarefa não é a de ensinar, mas, apenas, a de promover situações para o aluno fazer algo. Tudo o que o aluno faz é valorizado mesmo que se constate que ele começa a andar em círculos e não consegue ir além do que faz - na esperança de que, um dia, descubra a solução de seu problema. (CAGLIARI, 1998, p. 68)

Afirmando a interferência da língua oral no processo de evolução da escrita, o autor chega a questionar tanto a idéia de uma ordem de facilidade na aquisição (que fundamenta os métodos fônicos) como a 
idéia de estágios naturais, universais, que fundamentam a teoria construtivista por ele referida (CAGLIARI, 1998, p. 64).

Os trabalhos de Abaurre, por sua vez, têm-se desenvolvido sob uma perspectiva diferente. A autora, adotando um procedimento abdutivo (o qual consiste numa série ordenada de inferências lógicas), e comprometida com a análise daquilo que há de singular nos dados das suas pesquisas de campo, consegue dar respostas concretas a muitos dos anseios que permeiam as reflexões sobre alfabetização. Um dos pontos controvertidos, para o qual a autora propõe uma saída, diz respeito à relação entre oralidade e escrita:

Identifica-se, por um lado, a afirmação ingênua segundo a qual as crianças procurariam produzir uma escrita 'colada' na oralidade, de forma a representar, através das letras, os próprios sons da fala. Essa seria a tese da dependência radical da escrita à fala. A tese contrária, também ingênua, é representada pelos defensores da autonomia radical da escrita com relação à oralidade. Segundo esses, as práticas de escrita estariam totalmente 'imunes' aos efeitos da oralidade, por se tratar de modalidade que, ao longo do seu percurso evolutivo, teria já rompido quaisquer vínculos com o oral.

O dado em sua singularidade provoca naturalmente uma hipótese que se coloca no intervalo entre essas duas hipóteses radicais anteriormente mencionadas. Formula-se então a pergunta: e se a escrita se concebesse como uma modalidade autônoma, sim, a não ser confundida com a modalidade oral, mas estivesse sujeita, em determinadas circunstâncias, a contatos episódicos com o fônico? (ABAURRE, 1999, p. 172-173)

A autora defende que nem sempre a escrita da criança reflete exclusivamente a maneira como ela fala, e sim a maneira como ela reflete sobre a estrutura da língua que fala e sua forma de representação na escrita. Nesse sentido, a maneira como ela representa ou lê diferentes estruturas silábicas é fonte de profundas inferências teóricas: "As crianças, ao iniciarem a aprendizagem da escrita alfabética, começam também a analisar a estrutura interna das sílabas, reajustando suas representações fonológicas de forma a acomodar os constituintes das sílabas e sua hierarquia" (ABAURRE, 1999, p. 179). 


\section{OS PROCEDIMENTOS DA PESQUISA}

Este trabalho toma como base parte do corpus de uma pesquisa de campo, realizada durante todo o ano letivo de 2006, em escolas públicas da cidade de Salvador. Os informantes são 20 crianças em fase de alfabetização escolar, na faixa etária de seis a oito anos, oriundas de escolas públicas.

Foram realizadas, ao longo daquele ano, cinco sessões periódicas de leitura e produção de palavras e pseudopalavras com os mesmos sujeitos; o que permitiu um mapeamento longitudinal. Para este trabalho, selecionaram-se apenas os dados de produção, que foram levantados através de ditados de palavras e pseudopalavras. A opção por essa forma tradicional de levantamento de dados (ditado) deu-se porque fora a única possível, uma vez que se pretendia verificar a diferença entre estratégias de leitura e estratégias de escrita; assim, deveríamos utilizar, na produção, as mesmas palavras utilizadas no teste de leitura. Além disso, a maioria das palavras era conceitual (o que impossibilitava o uso de gravuras na elaboração de um ditado visual). Vale ressaltar que todas as palavras passaram por uma avaliação da familiaridade, sendo assim, todas as palavras utilizadas no teste eram familiares à criança. Dessa forma, tudo o que será dito aqui só poderá ser generalizado para a aquisição de palavras, conquanto tais resultados possam também contribuir para uma reflexão em outros níveis linguísticos (sintagmáticos, oracionais, textuais).

Os dados desse estudo de campo, por trazerem informações sobre crianças entre seis a oito anos, serão utilizados para inferir sobre as fases posteriores ao letramento emergente, ou seja, todos os sujeitos em estudo já superaram a hipótese de que se escreve com desenhos e de que o desenho é portador do sentido.

Por essa razão, com intuito de expor toda a progressão no processo de aquisição da escrita, para ilustrar as fases anteriores às dos sujeitos do estudo de campo, tomarei como base os dados que venho recolhendo de meu filho, doravante JP, através de diário parental, desde a idade de dez meses. JP está atualmente com oito anos, encontrando-se às voltas com as reflexões ortográficas sobre a escrita. 


\section{ANÁlISE DOS RESULTADOS: POR UMA NOVA CATEGORIZAÇÃO DOS ESTÁGIOS DE ESCRITURA}

Ao redimensionar os estágios de aprendizagem da escritura nos termos que aqui farei, tenho como intuito fornecer uma categorização dos níveis progressivos (e cíclicos) por que passam as crianças ao adquirirem a escrita de sua língua materna. Esta categorização está fundada num referencial diferente do tradicionalmente conhecido pelo alfabetizador (a teoria psicogenética) e visa explicar em que sentido o oral e o escrito se relacionam durante todo o percurso evolutivo da aprendizagem da escritura. Assim, tomo como base outro estudo (MOREIRA, 2003), em que mostro que a relação entre oral e escrito atravessa três grandes fases:

a) na primeira fase, oral e escrito desenvolvem-se lado a lado, sem uma necessária correlação, ou seja, a criança ainda não reconhece a escrita como representação da fala. Aqui é necessário fazer dois esclarecimentos: o primeiro é de que estou considerando escritura e leitura como processos diversos (embora relacionados); diferentemente do que faz a teoria construtivista, que trata indiferenciadamente processos de leitura e processos de escritura. Sendo assim, o que se diz sobre a evolução da produção escrita não pode ser necessariamente transposto para a leitura. O segundo esclarecimento é que, nesta fase, no que tange à leitura, há claros reflexos do oral sobre o escrito; haja vista as alterações prosódicas durante os eventos de leitura da criança, quando ela "finge" ler, cujas características são bem diversas da oralidade numa conversação. Todavia, isso não invalida a afirmação da independência inicial entre oral e escrito, visto que a criança ainda não utiliza o oral para decifrar ou ressignificar o escrito (para maiores detalhes acerca da leitura, remeto ao trabalho de 2003 citado acima);

b) na segunda fase, oral e escrito se correlacionam, assim, tanto se utiliza da fala para decifrar e compreender o escrito, como se observam reflexos da escrita na fala (um exemplo claro pode ser visto na fala de JP, quando, aos 5:10;02, passa a pronunciar os 
" $r$ " finais de algumas palavras). Assim, o que se observa é uma dependência de mão dupla entre escrito e oral;

c) na terceira fase, oral e escrito tornam-se modalidades diferentes, embora interdependentes. No dizer de Abaurre (1999), continua havendo "contatos episódicos" entre fala e escrita. Esses contatos episódicos vão se tornando cada vez menos frequêntes, passando a ocorrer, depois de adulto, em lapsos verbais ou desvios ortográficos em situações específicas (como a dificuldade de transpor para o registro escrito uma palavra usada quase exclusivamente no registro oral).

Os estágios de escrita serão apresentados de acordo com a divisão abaixo.
a) Escrita icônica;
b) Escrita grafemática;
c) Escrita fonográfica;
d) Escrita ortográfica.

Cada um desses estágios compõe-se de fases, as quais serão descritas a seguir.

\section{a) Escrita icônica}

Este estágio se caracteriza pelo momento em que a criança utiliza desenhos para representar o que deseja a alguém. Vale ressaltar, que, para diferenciar um simples rabisco de uma escrita, valho-me da intencionalidade; ou seja, só considero os desenhos da criança como escrita a partir dos dados em que há alguma manifestação explícita, por parte dela, do desejo de compartilhar o que fez com o Outro (inicialmente, quase sempre, sua mãe). No caso específico de JP, os primeiros rabiscos ocorreram com 1:11;01. Desde esse momento, havia um movimento do adulto (a mãe) no sentido de entender seus rabiscos, perguntando: "O que é isso que você fez aqui?"; mas o interesse manifesto por ele para esse compartilhamento iniciou-se por volta dos 2 anos de idade. 
Nessa fase, ele desenha rabiscos em forma de traços e linhas curvas e, ao descrever o que fez, quase sempre diz ter "feito" alguém conhecido. É importante frisar que quando a criança diz "eu fiz...”, não se pode afirmar que esteja categoricamente dizendo que quis "desenhar" alguém, e não "escrever" o nome de alguém, pois esses termos não são categorias semânticas bem definidas para a criança, como o são para nós, adultos letrados. Esses rabiscos conceptuais (com intenção de "dizer" algo) vão evoluindo em precisão gradativamente até atingirem a figuragirino, principal marca da primeira fase da escrita icônica, qual seja, a escrita icônica rudimentar.

A escrita icônica rudimentar caracteriza-se pela fase em que já há uma intenção manifesta na criança de representar algo da realidade para alguém, ou seja, há o que chamo de traçado conceptual. E seu protótipo seria a figura-girino, visto representar-se nela o início da relação entre concepção e precisão (GREIG, 2004, p. 38).

A fase seguinte consiste na escrita icônica sistemática, quando o traçado do desenho tem como protótipo o desenho esquemático. A diferença dessa fase para a anterior refere-se mais ao aspecto da precisão do que da concepção; ou seja, a intenção principal parece continuar sendo nominativa (os desenhos representam alguém ou alguma coisa); entretanto, os desenhos passam a ter uma maior precisão, já é possível um reconhecimento, pelo Outro, do que a criança está representando em matéria de traçado, não em matéria de concepşão. Daí porque a criança terá sempre que "interpretar" para o outro o que quer dizer.

A última fase é denominada escrita icônico-gráfica, caracterizada pelo momento em que a criança começa a perceber que o que se diz (concepção) não é representado pelo adulto através do desenho, mas através de um traçado que nada diz por si mesmo (dentro da sua concepção). No caso de JP, a constante observação da mãe (professora de Português e estudante de Doutorado), escrevendo e corrigindo trabalhos e, algumas vezes, a curiosidade manifesta em alguns episódios, como:

$$
\mathrm{JP}^{3} \text { : “O que você ta fazendo aí?”. }
$$

\footnotetext{
3 JP: Ao citar os dados recolhidos do diário parental, utilizarei sempre as iniciais JP para referir-me ao sujeito da pesquisa e M para referir-me à mãe, ou seja, neste caso, à investigadora.
}

MOREIRA - Os estágios de aprendizagem da escritura pela criança... 
M: "Tô escrevendo".

levou-o a manifestar essa intenção de dizer algo através do traçado a partir de 2:04;11.

Entretanto, o traçado sozinho não significa. Neste momento, acredito que a criança usa dois elementos distintos para representar os dois aspectos essenciais inerentes à escrita, quais sejam, respectivamente, "o que se diz" (conceito), representado pelo desenho, e o "como se diz" (neste caso, a fala), representado pelos rabiscos (o qual the serve de recurso para "interpretar" sua escrita). Gradativamente, a criança passa a apontar sempre para o rabisco para dizer o que escreveu; mas isso não significa ainda afirmar que ela já reconhece o caráter arbitrário da escrita. Ela aponta para o rabisco, simplesmente porque é o rabisco o "portador" da fala, como já afirmei acima, e não o desenho.

É importante esclarecer, finalizando esta fase, que a relação entre precisão e concepção nos desenhos infantis não é tão simples como essa exposição pode levar a crer. Segundo Greig

algumas crianças elaboram a figura-girino precocemente, antes mesmo de alcançar uma precisão perceptivo-motriz suficiente que the permita traçar uma figura fechada [...] enquanto outras chegam a isso mais tarde [...]. Precisão e concepção não caminham juntas. (GREIG, 2004, p. 38)

Assim, no caso específico de JP, cujo contato com adulto-escritor foi frequênte desde o nascimento, as tentativas de uso de rabiscos conceptuais (por volta dos 2 anos), ocorreram muito antes de ele construir um desenho esquemático da figura humana (por volta dos 4 anos e 11 meses). Por isso é que utilizei acima o termo protótipo para referir-me à escrita icônica sistemática.

Observe que essa classificação põe por terra a conhecida hipótese pré-silábica, visto que essa última terminologia não consegue dizer nada a respeito da concepção da criança sobre a escrita nessa fase, senão reafirmar a importância da fase posterior. E não abarca, por outro lado, as origens da relação oral/escrito que culminará na escrita silábica. No dizer de Cagliari:

Quando, numa fase inicial, uma criança tenta escrever fazendo bolinhas ou rabiscos, ela pode ir atribuindo um rabisco a cada 
palavra ou a cada sílaba que vai pronunciando. Esse sistema de escrita que está construindo e convencionalizando para si, nesse momento, é um sistema logográfico (representando palavras por caracteres individuais) ou silábico (representando palavras por caracteres isolados). Considerar este segundo tipo de escrita como pré-silábico é, sem dúvida, muito estranho e equivocado. $\mathrm{O}$ fato de não usar letras do nosso alfabeto não é argumento para ser 'pré-silábica`. Ela é, simplesmente, pré-letrada (do ponto de vista do nosso sistema de escrita). (CAGLIARI, 1998, p. 73)

\section{b) Escrita grafemática}

Embora o conceito de grafema esteja relacionado com o de fonema, utilizo o termo grafemática num sentido muito restrito (já que os termos existentes não dão conta do processo que descrevo aqui), para fazer referência ao momento em que a criança, ao perceber que a escrita utilizada pelo adulto não tem como caractere fundamental o desenho, começa a usar traçados puros nas suas tentativas de escritura. E isso é percebido tanto mais cedo quanto maior for o contato da criança com textos escritos. Por outro lado, ao se dar conta do caráter arbitrário do sistema de escrita, ela lança mão de tentativas para desvendar esse caráter, utilizando um sistema similar ao logográfico, mas ainda não compreende que a escrita representa partes da fala. Quando digo que seu sistema é "similar" ao logográfico seria porque, para considerar algo como logograma, ele precisa ser conhecido por sujeitos que o utilizem, ou, ao menos, pelo próprio indivíduo que o cria; o que não é o caso da criança, que dá a seu traçado um sentido totalmente contextual neste momento, ou seja, qualquer traço pode dizer qualquer coisa a depender do momento.

Essa fase pode ser assim caracterizado: no início, os rabiscos podem ter formas retas, curvas ou arredondadas (sua forma não interessa neste momento); ao aprender seu próprio nome, a criança passa a utilizar as letras desse nome fazendo uma série de combinações, mas essas letras não têm nenhuma relação aparente com o som.

Segue-se uma série de tentativas de compreensão da relação entre a escrita e o nome que se quer representar. Nesse nível, os trabalhos de Ferreiro trazem contribuições extremamente ricas levando em conta os critérios quantitativos (quantidade mínima e máxima de grafemas que a 
criança considera necessária para que algo faça sentido) e qualitativos (variância e posição no uso dos grafemas para que coisas diferentes sejam representadas por grafemas diferentes). A esse respeito, remeto à vasta literatura psicogenética.

A partir dos conflitos vividos ao utilizar esse critério, a criança começa a dar-se conta da relação entre escrita e oralidade. Mas o dar-se conta não a encaminha diretamente para a hipótese silábica, absolutamente. Alguns estudos mostram que ela costuma perceber inicialmente a relação entre letra e som inicial da palavra e, depois, letra e som finais, para, só depois, dar-se conta da sílaba (REGO, 1995). Mas isso é matéria para o próximo estágio.

\section{c) Escrita fonográfica}

O percurso que a criança segue até atingir a escrita silábica propriamente dita é um aspecto que tem ainda muito por ser explorado pela literatura. Aqui apenas tentarei traçar uma interpretação possível, tendo em vista os dados coletados, mas não será uma análise detalhada como mereceria tal matéria.

Nos dados da minha pesquisa de campo e do diário parental, observo uma tentativa de escrita da palavra que ultrapassa o estágio exclusivamente grafemático. E isso se observa na subvocalização utilizada pela criança no sentido de monitorar o que está escrevendo, além das marcas esparsas de letras que representam alguns sons da palavra-foco. Ao que parece, a criança começa a desejar escrever o que se fala, mas ainda não compreendeu o caráter linear da escrita, ou seja, ela percebe os sons salientes e procura representá-los, mas não na ordem em que ocorrem. A esse respeito, manifesta-se Cagliari:

Nem sempre [as crianças] procuram atribuir uma letra a uma sílaba, mas que observam os elementos vocálicos e consonantais da fala e escrevem representando essas saliências fonéticas que, às vezes, correspondem às sílabas e, às vezes, não. (CAGLIARI, 1998, p. 74)

Denomino essa como fase de escrita fonográfica difusa. Vejamos alguns exemplos desse tipo de representação, num dos sujeitos 
da pesquisa de campo: CAUBA (sábado), CAO (sapato), MROT (maestro) (Carolina ${ }^{4}, 6$ anos).

A prolação ocorrida durante a produção escrita, além da frequência de ocorrência de escritas similares, mostra que essas escritas não se deram ao acaso, e sim, foram representadas justamente as saliências fônicas, embora em ordens não-convencionais.

Como já afirmei antes, parece mesmo que a percepção do som inicial na fala geraria uma primeira tentativa de relacionar pares (primeiro som, primeira letra). Observo em JP, por volta dos 3 anos e meio, uma capacidade para perceber os sons iniciais das palavras, através de uma brincadeira que fazíamos: "Uma coisa começada com ... (som inicial)". Essa foi uma brincadeira que ele inventou com o primo e que passei a usar sempre. Algumas vezes, eu perguntava, outras, era ele quem o fazia. JP conseguia dizer uma série de palavras oralmente, todavia, na escrita, não relacionava o som com a letra inicialmente. Depois foi passando a preocupar-se apenas com o som inicial seguido do final, começando aos poucos a representá-los corretamente. Vejamos os exemplos abaixo, ocorridos aos 4:06:00: PDE MNAU (parede) [representa apenas o som inicial]; OEGUPEEDEDAU (olho) [representa som inicial e final, usando uma quantidade de caracteres não condizente com a quantidade da palavra-foco]; TOATUROU (televisão) [representa som inicial e final e uma quantidade de caracteres próxima à quantidade da palavra-foco].

Quando os sons que mereceram representação não foram mais quaisquer sons, mas, sim, sempre os sons iniciais e finais (conforme exemplos acima), observa-se uma sistematização incipiente, que ainda não significa uma escrita silábica. Pode-se dizer que a criança se encontra numa fase de escrita fonográfica pré-sistemática. Chamo-a de présistemática, para mostrar que, até então, a criança não se utiliza de nenhum critério estável para representar a fala. O primeiro critério estável a ser utilizado é o silábico, na fase seguinte.

Muito antes de começar a escrever numa hipótese fonográfica, JP já demonstrava uma sensibilidade à sílaba - alguns estudos têm mostrado que a sensibilidade para perceber a sílaba, enquanto unidade discreta, é

\footnotetext{
${ }^{4}$ Ao citar os dados recolhidos da pesquisa de campo, utilizarei o nome inicial do sujeito, ao invés de abreviatura, visto referir-se a um nome genérico, mantendo o necessário anonimato.
}

MOREIRA - Os estágios de aprendizagem da escritura pela criança... 
algo natural (McNEILAGE; DAVIS, 1990, 1993; CARVALHO, 2003; MOREIRA, 2009) - mas é aos 2:11;00 (com apenas quinze dias da sua entrada na escola, o que certamente não foi influenciado por ela) que o surpreendo "lendo" silabicamente (escandindo a palavra em sílabas). Estávamos em casa e ele me pediu para ler a história de "Pinóquio". Eu peguei o livro de Pinóquio e iniciou-se o diálogo abaixo:

M: "Mas este não é o livro de Pinóquio, não".

JP [insiste]: “É sim".

M: "Como você sabe que é?"

JP: “Ó aqui ó: pi - nó - quio. [escandindo oralmente mas mantendo o dedo parado no meio da palavra].

Esse e outros fatos levam-me a supor que a criança venha usando e refletindo (não conscientemente) sobre a sílaba durante sua aquisição oral desde a mais tenra idade. Entretanto, é a partir da fase silábica de escrita que tal conhecimento vem à tona e se torna mais consciente; ao mesmo tempo, essa longa experiência de manipulação do molde silábico durante a aquisição da linguagem também auxilia a aquisição da escrita. Nesse sentido é que me referi, no início deste capítulo, à relação de mão dupla entre escrita e fala.

No início, a criança nem sempre representa na escrita todas as sílabas que compõem a palavra, na ordem que se espera; omite algumas, repete outras ou inverte as posições. Além disso, nem sempre utiliza o conteúdo esperado para aquela sílaba (a vogal ou a consoante correspondentes), visto que lhe interessa representar não o conteúdo específico, mas o molde silábico. A esse tipo, denominei escrita fonográfica silábica rudimentar, porque ainda não alcançou o nível de sistematicidade máximo. Veja os exemplos: XASA (jacaré), MSA (madrasta), AET (tristeza) [escrita espelhada] (Railane, 6:11).

A fase posterior, que denomino escrita fonográfica silábica sistemática, representaria o momento de equilíbrio, em que a criança descobre uma maneira estável de escrever partes da fala, quais sejam, as sílabas. Dessa forma, ela elabora um sistema próprio, mas não se trata de 
uma idiossincrasia, visto ocorrer com todas as crianças do corpus, e ser retratado na literatura como fato generalizado para os usuários de escritas fonográficas. O sistema consiste em utilizar um caractere para cada sílaba que compõe a palavra. Se antes (na fase silábica rudimentar) nem sempre a criança representava todos os caracteres, ou utilizava qualquer caracter para representar a sílaba, agora ela passa a utilizar caracteres condizentes com a palavra-foco, seja uma vogal ou uma consoante. Exemplos de escritas silábicas sistemáticas (perfeitas): SPT (sapato), AIA (sabiás), CTO (castelo) (Juliana, 6:3).

Como atesta Ferreiro e Teberosky (1985), essa fase silábica é extremamente significativa, pois é durante ela que a criança passa a fazer uma análise mais sistemática da relação entre escrita e oralidade. Mas ela não é apenas significativa, como também necessária. Antes que a criança comece a perceber e representar a escrita fonograficamente, ou seja, cada segmento gráfico correspondendo a um segmento fônico, é condição sine qua non que ela tenha passado pela fase silábica.

Já foi dito que a escrita silábica é um momento de equilíbrio, em que a criança satisfaz-se com o sistema elaborado. Entretanto, esse sistema não condiz com a realidade. O contato da criança com o escrito - especialmente com "seu" nome escrito - contraria essa hipótese, e, ao tentar "ler" silabicamente, ela começa a se dar conta de que sobram caracteres. Simultaneamente, ela percebe que, ao usar o sistema silábico para escrever, palavras diferentes correm o risco de ser escritas da mesma maneira (Ex: AEU (cabelo), AEU (carteiro)). Assim, começa a desenvolver a sensibilidade para a percepção do conteúdo que compõe o molde silábico, mas, inicialmente, são as saliências fônicas que chamam a atenção, assim, passa a representar os fonemas, mas não todos os fonemas, e sim, aqueles que ganham uma saliência para ela, as demais sílabas continuam sendo escritas silabicamente. Cito abaixo alguns exemplos desse tipo de escrita: AVOI (árvore), FAIA (faísca), CABDO (sábado) (Alan, 6:11).

Denomino esse momento de fase de escrita fonográfica híbrida, pois hora caracteriza-se como silábica, hora, alfabética.

Finalmente, a criança passa a reconhecer o caráter fonográfico sistemático da escrita: quando cada letra representa um som. Embora essa hipótese também não condiga totalmente com a verdade, esse 
conhecimento é suficiente para que ela seja capaz de ler muitas palavras sem a ajuda dos outros e para que seja capaz de escrever palavras de maneira tal que não necessite mais de "tradução", como nas fases anteriores. Isso representa muito: representada seu "bilhete de entrada" para tornar-se leitor/escritor autônomo. Mas, diferenciemos, também aqui, dois tipos de escrita alfabética.

A escrita fonográfica alfabética pré-sistemática diz respeito àquela fase onde se observa, sim, uma consciência alfabética bem marcada, entretanto, nem sempre a criança utiliza a letra certa para representar o som determinado (excluindo os equívocos envolvendo regras ortográficas ou pronúncia diferente): ASGOLA (argola), CALULU (caruru) (Paulo, 6).

Os exemplos acima não parecem ilustrar um simples engano, se o observarmos com cuidado. Demonstram que a criança ainda se encontra em conflito quanto ao segmento sonoro que está representando e sua letra correspondente. No primeiro exemplo, temos um caso de conflito motivado por reflexões estruturais (a criança já percebe que /S/ e /L/ costumam ocorrer fechando a sílaba, e isso a coloca em conflito sobre qual elemento deve usar nesse momento; já que ela não está focada no som em si, mas no preenchimento do molde silábico, ou seja, numa reflexão sobre a estrutura da própria língua que fala). Muitos exemplos como esses estão presentes no nosso corpus. No segundo caso, os fonemas são muito próximos, do ponto de vista articulatório, e isso coloca a criança em conflito sobre qual letra usar. E não se trata aqui de ela escrever como fala (o falante acima não troca o fonema $/ \mathrm{r} /$ pelo $/ 1 /$ ), mas de ainda não representar com sistematicidade máxima os segmentos sonoros.

Quando essa representação torna-se mais fidedigna e atinge seu ponto máximo de sistematicidade, dizemos tratar-se de uma escrita fonográfica alfabética sistemática (ou perfeita). Os exemplos abundam: PRIVADA (privada), MILAGRI (milagre), TRISTESA (tristeza), PRARTICO (plástico), JACAREIS (jacarés). (Laila, 6).

Observe que, em muitos casos, a escrita não condiz com $\mathrm{O}$ esperado, ainda assim considero que essa criança esteja na fase da escrita alfabética sistemática, em virtude de estar representando, fielmente, a maneira como pronuncia a palavra no momento da escritura. 
Poderíamos dizer que, em sentido estrito, a criança que atingiu essa fase já está alfabetizada. Entretanto, não podemos dizer ainda que esteja letrada, visto que, para fazer uso da escrita, muitos outros aspectos necessitam ainda ser absorvidos, e a aprendizagem que se seguirá referese aos aspectos convencionais que regem uma dada escrita, enquanto produto de uma construção social e veículo de interação. Assim, a criança passa a aprender inicialmente a representar o que deseja respeitando determinadas regras de uso: do ponto de vista da compreensão, tanto faz escrever-se "casa" ou "caza"; entretanto, convencionou-se que a primeira é a escrita aceita. Superados os conflitos alfabéticos, a criança passa agora a lidar com as regras de uso da escrita. Ela está no nível de escrita ortográfica.

\section{d) Escrita ortográfica}

Esse estágio tem sido tema de inúmeros estudos, os quais demonstram que a compreensão do caráter ortográfico é, para a criança, fonte de extremas dificuldades, porque representa uma ruptura com o sistemático, com uma hipótese fundada na relação de elementos discretos perceptíveis. Agora ela terá que lidar com o imprevisto, o assistemático, o arbitrário. Ela entra na esfera do social.

Por outro lado, é intrigante observar que algumas marcas ortográficas de escrita podem ser encontradas em momentos esparsos do percurso evolutivo. Algumas são explicadas pelo fato de terem sido cristalizadas, memorizadas ou aprendidas globalmente, como por exemplo, nomes de pessoas. Outras, pela frequência com que aparecem na escrita ou com que são utilizadas pela criança com regularidade.

Esses casos deixam claro, portanto, que a despeito de uma tendência geral numa direção - nessa que acabei de expor - esses tipos de escrita não são necessariamente consecutivos, pois cada sujeito teria um percurso individual, e as vivências levariam a produções muito particulares. Isso me remete de volta à idéia de Abaurre (1999), segundo a qual, as pistas deixadas pelas crianças demonstram a existência de contatos episódicos entre oral e escrito. E por que não dizer que as arbitrariedades podem também aparecer episodicamente, em momentos inesperados?

MOREIRA - Os estágios de aprendizagem da escritura pela criança... 


\section{CONSIDERAÇÕES FINAIS}

A questão que apresento neste trabalho pretende muito mais estimular a reflexão em torno da temática dos níveis de escritura do que converter-se automaticamente numa nova classificação no âmbito escolar.

A questão está lançada para que outras discussões sejam abertas. Todavia, que não se perca de vista o objetivo central deste trabalho: a necessidade objetiva de construir uma nova categorização dos níveis de escrita fundada numa perspectiva linguística; especialmente fundada na relação fundamental entre escrita e oralidade.

Por outro lado, do que se disse aqui, conclui-se pela necessidade de um maior diálogo entre a escola e os pesquisadores que trabalham sob a perspectiva linguística, de modo especial, entre a Fonologia e a Alfabetização, cujo diálogo já rendeu valiosos produtos. Para isso, não é preciso desfazer os outros diálogos que já vigoram ao longo desses anos.

Mais do que nunca, que se resguarde cada papel na hierarquia educacional de uma vez por todas: aos pesquisadores, resta fornecer informações relevantes sobre o processo de aprendizagem dos alunos; aos coordenadores escolares, contribuir para a construção de uma metodologia que leve em consideração essas pesquisas, e, aos professores, levar a cabo esse ensino, visando efetivamente contribuir para formar um sujeito autonomamente letrado.

\section{REFERÊNCIAS}

ABAURRE, M. B. M. Posfácio - A aquisição da escrita do português: considerações sobre diferentes perspectivas de análise. In: ROJO, R. (Org.). Alfabetização e letramento: perspectivas linguísticas. Campinas: Mercado das Letras, 1998. p. 205-232.

. Horizontes e limites de um programa de investigação em aquisição da escrita. In: LAMPRECHT, R. R. (Org.). Aquisição da linguagem: questões e análises. Porto Alegre: EDIPUCRS, 1999. p. 17-38. 
ALVARENGA, D. Leitura e escrita: dois processos distintos. Educação Revista, Belo Horizonte, n. 7, p. 27-31, jul. 1988.

CAGLIARI, L. C. Elementos de fonética do português brasileiro. 1981. 185 f. Tese (Livre Docência) - Instituto de Estudos da Linguagem, Universidade de Campinas, Campinas.

Alfabetização e Linguística. 5. ed. São Paulo: Scipione, 1992a.

Da importância da prosódia para a descrição de fatos gramaticais. In:

ILARI, R. (Org.). Gramática do português falado - vol. II: níveis de análise linguística. Campinas: Editora da Unicamp, 1992b. p. 39-64.

A respeito de alguns fatos do ensino e da aprendizagem da leitura e da escrita pelas crianças na alfabetização. In: ROJO, R. (Org.). Alfabetização e letramento: perspectivas linguísticas. Campinas: Mercado das Letras, 1998. p. 61-86.

CARVALHO, W. J. de A. O desenvolvimento da consciência fonológica: da sensibilidade à consciência plena das unidades fonológicas. 2003. 330 f. Tese (Doutorado em Letras) - Instituto de Letras, Universidade Federal da Bahia, Salvador.

FERREIRO, E. Os processos construtivos de apropriação da escrita. In: . (Org.). Os processos de leitura e escrita: novas perspectivas. Porto Alegre: Artes Médicas, 1987. p. 102-123.

Reflexões sobre a alfabetização. São Paulo: Cortez, 1990.191 p.

. Passado e presente dos verbos ler e escrever. São Paulo: Cortez, 2002. 96 p.

Com todas as letras. Tradução de Maria Zilda Cunha Lopes. 14. ed. São Paulo: Cortez, 2007a. 104 p.

Alfabetização em processo. 18. ed. S. Paulo: Cortez, 2007b. 144 p.

FERREIRO, E; TEBEROSKY, A. A psicogênese da língua escrita.

Tradução de D. M. Lichstenstein et. al. Porto Alegre: Artes Médicas, 1985. 284p.

GADOTTI, M. Alfabetização e Letramento: como negar nossa história. 2005. Disponível em <http://www.paulofreire.org/twiki/pub/Institucional/ MoacirGadottiArtigosIt0004/AlfabLetramento_2005.pdf >. Acesso em: 25 jul., 2007. 
GREIG, P. A criança e seu desenho: o nascimento da arte e da escrita. Tradução de Fátima Murad. Porto Alegre: Artmed, 2004. 248 p.

KATO, M. O aprendizado da leitura. São Paulo: Martins Fontes, 1985. 122 p.

LEMLE, M. Guia Teórico do Alfabetizador. 7. ed. São Paulo: Ática, 1993. 72p.

MAYRINK-SABINSON, M. L. Reflexões sobre o processo de aquisição da escrita. In: ROJO, R. (Org.). Alfabetização e Letramento: perspectivas linguísticas. Campinas: Mercado de Letras, 1998. p. 123-159. (Coleção Letramento, Educação e Sociedade).

McNEILAGE, P.F; DAVIS, B. L. Acquisition of speech production: frames, then content. In: JEANNEROD, M. (Ed.). Attention and performance XIII: motor representation and Control. New Jersey: Lawrence Erlbaum Associates, 1990. p. 453-475.

Motor explanations of babbling and early speech patterns. In.: BOYSSON-BARDIES, B; SCHONEN, S. de; JUSCZYK, P.; MACNEILAGE, P.; MORTON, J. (Eds.). Changes in speech and face processing in infancy: a glimpse at developmental mechanism of cognition. Dordrecht: Kluwer, 1993. p. 34-58.

MOREIRA, C. M. Leitura e oralidade: caminhos que se cruzam. Letras de Hoje, Porto Alegre. v. 38, n. 2, p. 171-195, jun. 2003.

O estatuto da sílaba na aprendizagem da leitura: comparando o percurso de crianças e adultos. 2009. 292 f. Tese (Doutorado) - Instituto de Letras, Universidade Federal da Bahia, Salvador.

REGO, L. B. A relação entre a evolução da concepção de escrita da criança e o uso de pistas grafo-fônicas na leitura. In: CARDOSO-MARTINS, C. (Org.). Consciência fonológica e alfabetização. Petrópolis: Vozes, 1995. p. 69-100.

REGO, L. B; BUARQUE, L. L. Algumas fontes de dificuldades na aprendizagem de regras ortográficas. In: MORAIS, A. (Org.). $\mathbf{O}$ aprendizado da ortografia. Belo Horizonte: Autêntica, 2002. p. 21-41.

ROJO, R. (Org.). Alfabetização e Letramento: perspectivas linguísticas. Campinas: Mercado de Letras, 1998. 198 p. (Coleção Letramento, Educação e Sociedade)

SILVA, C. S; BRANDÃO, A. C. P. Reflexões sobre o ensino e a aprendizagem da pontuação. In: MORAIS, A. (Org.). O aprendizado da Ortografia. Belo Horizonte: Autêntica, 2002. p. 121-139. 
SILVA, M. S; MOREIRA, C. M. Interferência da ilustração na aquisição da leitura. 2003. Disponível em: < http://www.uesc.br/seminarioic/sistema/ resumos/10_pag293.PDF $>$ Acesso em 12 jul, 2007.

TERZI, S. B. A construção da leitura: uma experiência com crianças de meios iletrados. Campinas: Pontes, 1995a. 165 p.

Recebido em 12/12/07. Aprovado em 16/07/09.

Title: Children's writing acquisition stages: a new reading of an old theme

Author: Cláudia Martins Moreira

Abstract: This paper reviews the acquisition stages of writing based on the principles of Applied Linguistics, and offers an alternative to the well-known Ferreira's stages, which are largely used by literacy teachers. In order to reach that goal, I use the findings and conclusions provided by studies on writing acquisition, from a phonological basis (ABAURRE, 1998, 1999; CAGLIARI, 1992a, 1992b, 1998), as well as the fundingis of studies on language acquisition that focus on the role of the syllabic mode in the acquisition process (MC NEILAGE; DAVIS, 1990). The corpus is composed of notes from field and experimental research carried out in public schools in Salvador, in five individual meetings of writing production. These writings allow me to conclude that the writing acquisition path starts with the absence of a graphicphonic relation, goes through a series of cyclic stages of relations between sound/letter, until these stages reach orthographic relations, whose sound/graphic dependence is overcome.

Keywords: writing; phonology; acquisition; literacy; stages.

Titre: Les stages d'acquisition de l'écriture par l'enfant : une nouvelle lecture pour un ancien sujet

Auteur: Cláudia Martins Moreira

Résumé: Ce travail présente une révision des stages différents de l'acquisition de l'écriture à travers la Linguistique Appliquée, comme alternative à ceux, déjà connus, d' Emília Ferreiro, très employés par le professeur qui fait l'alphabétisation. Ainsi, nous emploierons les résultats et conclusions fournis par les études sur l' acquisition de l'écriture sous une orientation phonologique (ABAURRE, 1998, 1999; CAGLIARI, 1992a, 1992b, 1998) ainsi que les études d'acquisition du langage qui mettent en évidence le rôle de la syllabe dans le processus d'acquisition. (MC NEILAGE \& DAVIS, 1990). On s'en servira des enregistrements de la recherche de champ et de la recherche expérimentale qui ont eu lieu tout au long de l'année scolaire 2006, avec 20 enfants issus d'écoles publiques de la ville de Salvador, pendant 5 rencontres périodiques individuelles de production écrite. Telles productions permettent de conclure que le parcours de l' acquisition de l'écriture commence par l' absence de relation grapho-phonique, puis passe par une série d'étapes cycliques de relations son/lettre, jusqu'à atteindre les relations orthographiques dont la dépendance 
son/graphie est dépassée.

Mots-clés: écriture; phonologie; acquisition; alphabétisation; stages.

Título: Las etapas de adquisición de la escritura por el niño: una nueva lectura para un antiguo tema

Autor: Cláudia Martins Moreira

Resumen: Este trabajo hace una revisión de las etapas de adquisición de la escritura a la luz de la Linguística Aplicada, y provee una alternativa diversa de las conocidas etapas ferreirianas, muy utilizadas por el profesor alfabetizador. Para tal, utilizo hallados y conclusiones fornecidos por los estudios de adquisición de la escritura, de orientación fonológica (ABAURRE, 1998, 1999; CAGLIARI, 1992a, 1992b, 1998), así como de estudios de adquisición del lenguaje que evidencian el papel del molde silábico en el proceso de adquisición (MC NEILAGE; DAVIS, 1990). Son utilizados, como sistemas escritos, los registros de la investigación de campo y experimental realizada a lo largo del año lectivo de 2006, con 20 niños de escuelas públicas de la ciudad de Salvador, en cinco encuentros periódicos individuales de producción escrita. Tales producciones me permiten concluir que el recorrido de la adquisición de la escritura se inicia con la ausencia de relación grafo-fónica, pasando por una serie de etapas cíclicas de relaciones sonido/letra, hasta alcanzar las relaciones ortográficas, cuya dependencia sonido/grafía es superada.

Palabras-clave: escritura; fonología; adquisición; alfabetización; etapas. 